\title{
С.Н. Дубровина
}

Московский государственный гуманитарный университет

\section{Жанр монодрамы в творчестве С. Беккета и в театре абсурда}

Аннотащия: Статья посвящена исследованию жанра монодрамы в театре абсурда. Выявляются основные причины интереса к этому маргинальному жанру в эпоху 1950-60-х гг. На основе анализа текстов пьес С. Беккета, Ж. Вотье, Р. Пенже изучаются особенности поэтики монодрамы в кризисный период в истории западноевропейского театра.

The article deals with the distinguishing features of the genre of monodrama in the theatre of the $1950-60^{\text {th }}$ (S. Beckett, J. Vauthier, R. Pinget). In the article are considered the main reasons of the interest in this genre as well as the poetics of the monodrama of the Theatre of the Absurd.

Ключевые слова: монодрама, творчество С. Беккета, театр абсурда.

Monodrama, Theatre of Samuel Beckett, Theatre of the Absurd.

ББК: 83.3(0).

Контактная информащия: Москва, ул. Верхняя Радищевская, 16/18. МГГУ, филологический факультет. Тел. (495) 6720490. E-mail: svetlana.dubrovina@gmail.com.

Жанр монодрамы имеет в западноевропейском театре давнюю историю. К монодраме обращались драматурги разных эпох, и каждый раз по сути рождался новый жанр, который по формальному признаку, - пьеса для одного актера, можно было назвать монодрамой. Во французском театре после всплеска интереса к монодраме в эпоху символизма, в 1950-1960-е гг. к жанру монодрамы обращаются драматурги, творчество которых принято объединять под названием «театр абсурда»: Сэмюель Беккет («Последняя лента Крэппа», 1958, «Счастливые дни», 1961, поздние пьесы), Жан Вотье («Персонаж сражающийся», 1955), Робер Пенже («Гипотеза», 1964).

Причин такого интереса к маргинальному драматическому жанру несколько. Обращение к жанру монодрамы в этот экспериментальный период в истории западноевропейского театра обусловлено прежде всего кризисом диалога, фундаментального для этой эпохи сомнения в естественности межличностных отношений между персонажами и, следовательно, в возможности развития драматического конфликта от завязки к развязке [Sarrazac, 2005, p. 66].

Диалог оказывается невозможен, он истощается ${ }^{1}$. В прямом смысле такое истощение диалога происходит в творчестве Беккета от раннего к позднему периоду, начиная с первой законченной пьесы «В ожидании Годо» (1952) (до этого была незавершенная «Элевтерия»), в которой четыре полновесных персонажа (Владимир, Эстрагон, Лаки, Поццо), один с маленькой ролью (Мальчик) и один отсутствующий на сцене (Годо). В «Эндшпиле» (1957) уже только два главных персонажа (Хамм и Клов), а два других, Нелл и Нагг, эпизодически выныривают

1 «L'Epuisé» - «Опустошенный» (в пер. C. Исаева), или «Истощенный», как назвал свою статью о Беккете Жиль Делёз. 
из своих мусорных баков, в «Счастливых днях» (1961), где формально участвуют два персонажа - Винни и Вилли, - Вилли большую часть прячется в канаве и изредка издает отдельные слова и звуки. В «Последней ленте Крэппа» (1958) только один герой, Крэпп, а также и запись его голоса на магнитофонную ленту. Наконец, в поздних пьесах Беккета на смену полноценному персонажу приходят «обрывки», части персонажа - Мужской силуэт («Призрачное трио», 1975), Рот («Не я», 1972) и т.п. Нужно отметить, что похожий процесс происходит и в романистике Беккета: о постепенном исчезновении Другого в трилогии Беккета «Моллой», «Мэлон умирает» и «Безымянный» пишет в своей статье «В ожидании Арто» Дани-Робер Дюфур [Dufour, 2002, p. 73-91] .

В то же время, уже в самой первой пьесе, где формально действует пять персонажей, по мнению многих исследователей, главные герои Владимир и Эстрагон больше похожи на ego и alter ego одного лица, чем на два независимых индивидуума. Так же как можно назвать «парными» персонажами Лаки и Поццо, которые во втором действии меняются местами: «палач» становится «жертвой» и наоборот. Такое максимальное сходство - вплоть до полного тождества - характеризует многих «парных» героев Беккета: например, в пьесе «Экспромт в Огайо» два персонажа, Слушатель и Чтец, должны быть «насколько возможно похожи» [Beckett, 1986, p. 59]. Они почти неразличимы, двойники, но первый молчит, второй - читает. Это две «стороны», две ипостаси, ухо и рот, одного лица. Максимально похожи, как близнецы, и герои Ионеско Мартены и Смиты в «Лысой певице», и это лишает их возможности вступать в диалог.

Итак, сама классическая драматическая форма, подразумевающая «естественный» разговор двух или нескольких персонажей, в середине XX века представляется несостоятельной. Начиная с театра абсурда, - и даже раньше, с «новой драмы», в современном театре можно с уверенностью говорить только об одной форме диалога - о диалоге между зрителем и сценой, между текстом и зрителем ${ }^{2}$. В этом смысле можно сказать, что даже те пьесы театра абсурда, которые формально написаны для нескольких персонажей, становятся монодрамами в том смысле, что в них звучит только один голос - голос самого текста.

Появление пьес-монологов в театре абсурда во многом обусловлено новым отношением к слову. С одной стороны, слово в театре 1950-х гг. становится самодостаточным - то есть самостоятельным, а не вспомогательным элементом. Слово больше не воспринимается драматургом только как инструмент для передачи внутреннего мира персонажа, его социальных и психологических характеристик, сюжета пьесы и пр., но становится самим действующим лицом пьесы, движущей силой развития действия, формирует интригу и сюжет. Как следствие, одного «источника голоса» и сцены оказывается достаточно для театра, исчезает необходимость в других персонажах. В то же время в театре абсурда окончательно утверждается равнозначность всех «языков» театра наравне со словом: декорации, костюмы, жесты, музыка, звуки и пр.

Ионеско называл свои пьесы «языковыми трагедиями», тем самым подчеркивая, что в его театре речь идет об игре языком и с языком. Беккет подошел еще

${ }^{1}$ В названии статьи Дюфура, «En attendant Artot», намеренно искажается имя Арто (наст. Artaud), с тем чтобы появилась отсылка, с одной стороны, к беккетовскому Годо (Godot), a, с другой, к излюбленной Арто игре со своим именем.

${ }^{2}$ См. об этом подробнее: теоретик театра Патрис Пави: «В современных текстах публике адресовано единое целое текста, или скорее не адресовано, а брошено на нее. Диалог теперь возможен только между текстом и зрителем» [Pavis, 2002, p. 217]. Современный французский театровед и драматург Жан-Пьер Сарразак: «Если еще существует диалог, конечно, в чисто метафорическом смысле, - это может быть только диалог между залом и сценой... Это современный зритель находится в ситуации “диалога”. А не персонажи» [Sarrazac, 2005, p. 68]. 
дальше к границам театральности, в его пьесах в качестве одного персонажа монодрамы выступает даже не одно лицо, а лишь какая-то его «часть» - как Рот в пьесе «Не я», например.

Другой вариант такой «самостоятельности» языка в театре - не языковые игры, как в пьесах Беккета «В ожидании Годо» или Ионеско «Лысая певица», а лирическая стихия, характерная для пьесы Беккета «Последняя лента Крэппа». Лирическая, поэтическая стихия, по мнению одного из первых в нашей стране исследователей творчества Беккета Майи Кореневой, определяет поздние беккетовские тексты: «70-е годы внесли новый акцент в творчество Беккета. Изменения коснулись и прозы, и драматургии. Они возвестили о себе напором лирической стихии, еще более размывшей повествовательное начало и, по существу, вытеснившей комическое. Произведения, написанные в этом ключе, такие, как «Общение» (1980), «Плохо увиденное, плохо сказанное» («Mal vu, mal dit», 1981), «Качи-кач» («Berseuse», 1981), и другие, отличает особая, поэтическая по своей природе структура, тяготеющая по характеру высказывания к лирике. Впервые она отчетливо предстала в пьесе «Последняя лента Крэппа» (1958). Примечательно, что в пьесах этого времени доминирует форма монодрамы, в которой лирический элемент выявляется как раз сильнее всего» [Коренева, 1999, с. 16].

Что касается метафизической подосновы «истощения» диалога в театре абсурда, то можно было бы привести множество свидетельств, поясняющих это явление, отсылающих к страшным событиям в истории ХХ века, а также исследований, в которых утверждается преемственность театра абсурда по отношению к философии экзистенциализма. Не углубляясь специально в эту тему, мне хочется дать только ссылку на слова Вальтера Беньямина из эссе о Лескове «Рассказчик» (1936), где философ, размышляя о постепенном исчезновении рассказчика из жизни и литературы в XX веке, объясняет это явление тем, что судьба одного человека никого больше не интересует, а передавать опыт Другому уже оказывается невозможно: «Разве мы не заметили, что, когда закончилась война (Первая мировая война. - С.Д.), люди пришли с фронта онемевшими? Вернулись, став не богаче, а беднее опытом, доступным пересказу? Поток книг о войне, хлынувший на нас через десять лет, содержал в себе все что угодно, но только не опыт, передаваемый из уст в уста» [Беньямин, 2004, с. 384].

Невозможность диалога имеет двойную природу: с одной стороны, в силу отталкивания от Другого, нежелания прислушиваться к Другому, а с другой стороны, - в силу отсутствия полноценного осознания самого «Я», которое вступает в диалог. Интересно отметить, что с точки зрения современного богословия, диалог - это прежде всего встреча, которая неразрывно связана с радостью, ликованием, то есть выявлением лика другого человека ${ }^{1}$. Возможна такая встреча только при основном условии, которое можно было бы назвать условием открытости «Я»- «Другому» (Митрополит Антоний называет его «условием уязвимости»), от которой современный человек обычно закрывается иронией, юмором. Театр абсурда демонстрирует полную противоположность такому истинному диалогу: герои максимально закрыты, не слушают и не слышат, а о радости от общения в этих пьесах говорить не приходится. Даже если в пьесе есть два или несколько героев, подлинной встречи не происходит - не только потому, что две личности не желают вступать в контакт, но и потому, что личности, «лика», нет - выявлять нечего, герои максимально лишены индивидуальности.

${ }^{1}$ Об этом пишет в своих работах Митрополит Антоний Сурожский, я привожу его идеи в изложении философа Александра Филоненко, представленном им на лекции в рамках семинара, посвященного осмыслению духовного наследия Митрополита Антония из цикла «Человек в общении», проходившем 19 апреля 2010 г. в «Доме Русского Зарубежья» (Москва). 
Однако отсутствие единого целого личности персонажа не означает, что он превращается в некое «пустое пространство». Напротив, персонаж, его «оболочка», заполняется множественными голосами, голосами из прошлого и настоящего, голосами вымышленными и реально существовавшими (существующими) в жизни героя. При этом герой перестает быть «собой», он лишается самого себя, своего тела, преобразуясь всего лишь в точку пересечения разных голосов: так у Беккета появляются Рот из «Не я», воспроизводящий обрывочные мысли и воспоминания; персонаж Джо из телевизионной пьесы «А, Джо?», который ничего не говорит на сцене, но в голове которого непрерывно звучит голос давно ушедшей в небытие женщины, в свою очередь припоминающей ему голоса других позабытых им близких людей; Припоминающий (Souvenant ${ }^{1}$ ) из пьесы «На этот раз», с трех сторон от которого, слева, справа и сверху, раздаются голоса одного и того же человека - его самого. Беккетовский персонаж вмещает в себя множество «фантомных существ» [Sarrazac, 1989, p. 129], бесконечных состояний человека.

Источником этих голосов чаще всего становится прошлое героя, с которым персонаж ведет своеобразный диалог. Однако целью такого диалога с прошлым, в отличие от, скажем, прустовской попытки возвратить время, становится не остановить мгновенье, не «поймать» прошлое, а, скорее, избавиться от него. Так происходит в пьесах Беккета «Последняя лента Крэппа», «Счастливые дни», «Качи-Кач» и др.

Диалог с прошлым определяет и драматический конфликт в пьесе Вотье «Персонаж сражающийся»: у Вотье герой - профессиональный писатель - пытается вернуть себе пылкое творческое состояние начинающего молодого автора через пятнадцать лет, у Беккета встреча 69-летнего Крэппа с самим собой в молодости происходит через тридцать лет. Существенная разница между героями Беккета и Вотье состоит в том, что Персонаж сражающийся льстит себе надеждой, что сможет исправить рукопись юнца, которым он был когда-то. И это ему даже в какой-то мере удается - его слог стал более изысканным, художественным; но, в то же время, и менее искренним, из его нынешнего текста ушла жизнь. Персонаж осознает это, но продолжает борьбу за свое творение. В пьесе Вотье еще сохраняется модернистский пафос битвы за смысл, за живой источник в творчестве, несмотря на то, что драматург подчеркивает в предисловии к пьесе ложность посылок своего героя: «Он будет писать этот роман, - комментирует Вотье, - самодовольно или с неловкостью, и со всем сердцем, и с тоской; он будет писать его патетично, он так прикипит к этой работе, что прикоснется к возвышенной области человеческого мужества. Но и это он сделает, всего лишь ошибаясь» [Vauthier, 1981, p. 17] $]^{2}$.

Основной пафос Персонажа Вотье - начать все сначала, снова бороться за свежесть и искренность слов. Крэпп, наоборот, осознает, что жизнь уже ушла, он не только не пытается дописать, добавить, исправить что-то в записи тридцатилетней давности, он отрицает свое прошлое, отрекается от него, он сдается: «Только что прослушал кретина, каким выставлялся тридцать лет назад, даже не верится, что я когда-то был такой идиот. Слава Богу, с этим со всем покончено... <...> И сказать-то нечего, ничего не выжмешь» [Беккет, 1999, с. 220].

Так и в «Гипотезе» Пенже Мортен постепенно умолкает под напором слов своего собственного Изображения, последняя реплика которого утверждает необходимость молчания: «Упущенные возможности промолчать... Упущенные возможности...» [Pinget, 1987, p. 46]. Герой Пенже вступает в диалог не со своим текстом (записью), сделанными в прошлом, а с самой возможностью существования написанного им текста и, соответственно, подвергает сомнению существова-

${ }^{1}$ В оригинальном, англоязычном варианте, этот персонаж называется Listener - Слушатель.

2 Перевод текста пьесы мой. 
ние себя самого как автора. В финале пьесы Мортен выбрасывает свою рукопись, а на его место чтеца заступают Изображения Мортена, все более и более масштабные, скандирующие текст рукописи все более громко и напористо.

В трех рассматриваемых монодрамах театра абсурда нет Другого - и в силу выбранного драматургами жанра, и в силу более фундаментальной для эпохи невозможности, отсутствия, недоступности Другого (традиционная монодрама, напротив, не исключает, а, скорее, предполагает присутствие Другого, пусть и за границами сцены: например, в пьесе Жана Кокто «Человеческий голос» (1934) присутствие возлюбленного героини за телефонной трубкой явно ощутимо). В силу этого в театре абсурда возрастает роль вещей, предметов, декораций, в какой-то мере заменяющих герою объект общения. Особое отношение к материальному миру складывается уже в экзистенциалистской философии и литературе вспомним Рокантена, героя романа Сартра «Тошнота», который, осознав существование этого материального мира, испытывает чувство отвращения от чудовищного плотского присутствия здесь и сейчас корней, выпущенных деревом на поверхность земли, или кружки пива и т.п. А современники Беккета и Ионеско «новые романисты» вообще предлагали заменить в литературе психологические портреты персонажей описанием геометрических свойства предметов (этот метод использует А. Роб-Грийе в сборнике рассказов «Моментальные снимки»).

Наиболее кардинально функция предмета на сцене трансформируется в пьесе Беккета. Известно то внимание, которое Беккет, драматург и режиссер, уделял реквизиту, с которым работали актеры в его постановках: морковка, шляпа, ботинки, веревка и чемодан в пьесе «В ожидании Годо», зонтик и сумка Винни со всем ее содержимым в «Счастливых днях», приставная лестница, платок Хамма в «Эндшпиле» и др. Сам драматург, выступая в качестве режиссера в разных постановках «Последней ленты Крэппа» ${ }^{1}$, подчеркивал, в частности, особую роль эпизодов с бананом: колебания героя «есть или не есть» связаны, по мнению многих исследователей, с манихейским противопоставлением светлого-темного, прочитывающимся и на других уровнях пьесы: например, в разграничении пространства на светлое, над столом Крэппа, и темное вокруг стола, и особенностей перемещения героя из одного пространства в другое. Но совершенно особую роль в этой пьесе выполняет Лента, и не только как источник голоса 39-летнего Крэппа, но и как предмет, к которому обращены внимание и даже в какой-то степени ласка и любовь Крэппа. Не случайно драматург варьирует ласковое обращение персонажа к Ленте: «Кату-у-ушка! (Блаженная ульбка.) <...> Ага! Вот ты где, плутишка!» [Беккет, 1999, с. 213], а Беккет-режиссер настаивал на том, что в финале пьесы его герой должен практически ложиться на магнитофон, как в эпизоде с лодкой много лет назад зарывался в груди девушки молодой Крэпп.

Похожей функцией обладает пишущая машинка в пьесе Вотье (вполне возможно, что этот образ отсылает к пьесе Жана Кокто «Пишущая машинка»), этот сакральный предмет, с которым связаны прошлые и нынешние ожидания Персонажа, профессионального писателя. Однако если у Беккета сама Лента воплощает для Крэппа ушедшие образы прошлого, то герой Вотье все-таки относится к машинке как к инструменту, правда, самым тесным образом связанному с творческим процессом: так мы видим его «виртуозно стучащим по клавишам» после того, как звуки поездов напомнили ему о прошлом [Vauthier, 1981, p. 38]. Но, кроме того, значительна роль отдельных предметов в комнате дешевенькой гостиницы, где происходит действие «Персонажа сражающегося»: окно, открывающее для героя его прошлое через мир звуков (звуки поезда, которые звучали и тогда, давно); дверь как связь с внешним миром; кресло, которое Персонаж сначала

${ }^{1}$ В постановке в Шиллер-Tеатре (Schiller-Theater Werkstatt) в Берлине в 1969 г., в Пети Театр д’Opce (Petit Théâtre d'Orsay, Paris) в 1975 г. и др. см.: [McMillan, 1988, p. 241$312]$. 
выпрашивает, а потом и требует у Гарсона, поскольку только оно может вернуть его к воспоминаниям о прошлом, - почти как магическая прустовская мадленка, кусочек печенья, который возвращал героя эпопеи «В поисках утраченного времени» Марселя в его детство.

В пьесах Беккета, Вотье, Пенже практически нет сюжета в традиционном смысле этого слова. За счет чего авторы добиваются в таком случае драматического развития действия, каким образом организуется структуры пьесы? Жан Вотье сказал по поводу своей драмы: «Мне нужно было сделать драматичной нечто анти-театральное; нужно было, чтобы жизнь на сцене родилась из чтения текста публике» [Vauthier, 1981, p. 15]. То же самое можно было бы отнести и к пьесе Беккета, у которого театральным должен был стать процесс слушания записи Ленты, и к драме Пенже, где герой монотонно зачитывает наизусть некий текст.

Тем не менее, даже в совсем небольшой по объему пьесе Беккета исследователи различают несколько «частей», точнее, эпизодов, у которых даже появились условные названия: воспоминание о смерти матери, эпизод с лодкой. С одной стороны, приведенная выше мысль Вальтера Беньямина об исчезновении «рассказчика» и, следовательно, рассказываемых историй, из литературы (напомним, статья была опубликована в 1936 г.) в наибольшей степени касается ситуации 1950 - 1960-х гг., когда теоретики и практики «нового романа» и «театра абсурда» предлагали создавать литературу по возможности вообе без историй. Однако этот эксперимент показал, что абсолютный отказ от сюжетности в литературе невозможен, и, отвергая сюжет как основу, остов произведения, авторы 1950 1960-х гг., тем не менее, прибегают к использованию отдельных историй или их фрагментов, которые мозаично соединяют по ходу романа, пьесы, и последовательность которых, пусть и произвольная, формирует структуру произведения (например, история с солдатом и ее вариации в романе А. Роб-Грийе «В лабиринте», история о процессе создания романа в «Золотых плодах» Натали Саррот, история об умирающем мальчике, которую рассказывает Хамм в пьесе Беккета «Эндшпиль» и др.).

Так и все три обсуждаемые драмы, «Гипотеза», «Персонаж сражающийся» и «Последняя лента Крэппа», посвященные теме «автор и его произведение», «творец и его творение», в первую очередь ставят под вопрос традиционное представление об авторе как создателе «историй». И, тем не менее, именно обрывочные истории являются своеобразными кульминационными моментами, местом наибольшего драматического напряжения: в пьесе «Гипотеза» это история о девушке и ее умершем отце в двух интерпретациях, в «Последней ленте Крэппа» уже упоминавшиеся эпизоды смерти матери и эпизода с лодкой.

Что касается «Персонажа сражающегося» Жана Вотье, то динамическое развитие действия происходит здесь в первую очередь за счет музыкальных способов организации текста. Жан-Луи Барро, первый интерпретатор роли Персонажа, подчеркивал, что у Вотье было музыкальное образование, и даже называл его «прекрасным музыкантом» [Vauthier, 1981, p. 10], имея в виду построение пьесы. Пьеса делится на секвенции, и ритм становится здесь категорией, отображающей (заменяющей) развитие действия, драматического конфликта. Недаром подзаголовком к пьесе драматург выбирает музыкальный термин, «фортиссимо». Пьеса построена по принципу симфонии, и роль музыки и звуков в организации ритмического поля драмы первична: иногда персонаж прислушивается к звукам, иногда он говорит одновременно с ними, иногда звуки перебивают его. Можно сказать, что персонаж вступает в диалог с окружающим его звуковым пространством (как собственно со звуками, издаваемыми людьми за перегородками комнаты в гостинице, где он находится, так и со звуками, скажем, дождя или приближающегося поезда).

Роль звуков в этой пьесе Вотье принципиальна. Они создают на сцене действие, инсценируют саму жизнь, проходящую вокруг (или мимо?) Персонажа: звуки 
вокзала, где периодически проносятся дальние поезда, звуки двух парочек из соседних номеров, которые проводят время каждая на свой манер, шаги по лестнице, постукивания кулаком в перегородки и т.д. Вотье даже специальным образом записывает текст, чтобы дать режиссеру и читателю понять одновременность и взаимную связанность слов Персонажа и звуков: страница разделяется на две колонки, в левой автор записывает звуки («Туки-туки-туки-туки»), в правой дается или ремарка, описывающая жесты и движения Персонажа, или его реплика.

Нужно отметить, что в «Последней ленте Крэппа» роль звуковой составляющей постановки также достаточно значима, и в первую очередь благодаря тому, что сама структура пьесы выстроена на противопоставлении моментов «слушания» - «не-слушания» Крэппом магнитофонной записи, причем Беккет в своих режиссерских дневниках выверяет длительность этих моментов с максимальной точностью, до секунды [McMillan, 1988, p. 262]. Кроме того, чрезвычайно важным драматург считал тонкую нюансировку двух голосов одного человека, Крэппа 39-летнего и 69-летнего, без излишней стилизации последнего под голос «старика». Драматичность действия достигается в этой пьесе также за счет противопоставлений тонов голоса Крэппа 69-летнего: вопросительный, восклицательный, мечтательный. Движение голоса Крэппа, его игра с Лентой, то слушание, то не-слушание (мечтательный взгляд в пустоту, в то время как Лента продолжает крутиться), то внезапная остановка, прерывность производимой им новой записи (забывает включать Ленту, забывает выключать ее) также формируют течение драматического действия.

Движения и жесты персонажей также становятся максимально функциональны в организации структуры пьес: таковы перемещения Крэппа извне вовнутрь светлого пространства вокруг стола и наоборот; движения Персонажа сражающегося - методичные, или резкие, или истеричные, в зависимости от происходящих в нем перемен, от стола с пишущей машинкой, к окну, к стене, к двери; перемещения Мортена от стола с рукописью к библиотеке.

На примере этих трех пьес можно констатировать, что эпоха 1950 - 60-х гг. рождает новый тип монодрамы, наследующей евреиновскому представлению о монодраме как об отражении предельной субъективности современного театра, представляющего события на сцене с точки зрения одного лица даже в том случае, если формально в пьесе участвуют несколько персонажей; воплощающей предвидения Антонена Арто о новом отношении к жесту, движению актеров, декорациям, сценическому реквизиту, звуковому оформлению постановки и пр. как равноправным «языкам» театра наравне со словом; реализующей экзистенциалистскую метафизику тотального одиночества человека перед лицом непостижимого мира, затопляющего его своей материальностью.

\section{Литература}

Беккет С. Театр: Пьесы: Пер.с англ. и фр. / Сост. В. Лапицкого; вступ. ст. М. Кореневой. СПб., 1999.

Беньямин В. Маски времени: Эссе о культуре и литературе. СПб., 2004.

Коренева М. Невыразимая доступность небытия // Беккет С. Театр: Пьесы: Пер. с англ. и фр. СПб., 1999.

Beckett S. Catastrophe et autres dramaticules. Paris, 1986.

Dufour D.-R. En attendant Artot // Europe. Paris, 2002. N 873-874.

McMillan D. Beckett in the theatre. N.Y., 1988. Vol. I.

Pavis P. Dictionnaire du théâtre. Paris, 2002.

Pinget R. L'Hypothèse suivi de Abel et Bela. Paris, Les éditions de Minuit, 1987.

Sarrazac J.-P. Dialogue (crise du) // Lexique du drame moderne et contemporain / Dirigé par J.-P. Sarrazac. Belval, 2005.

Sarrazac J.-P. Théâtres intimes: Essai. Paris, 1989.

Vauthier J. Le personnage combattant: pièce en deux parties. Paris, 1981. 